\title{
Gja1 acts downstream of Acvr1 to regulate uterine decidualization via Hand2 in mice
}

\author{
Hai-Fan Yu, Zhan-Peng Yue, Kai Wang, Zhan-Qing Yang, Hong-Liang Zhang, \\ Shuang Geng and Bin Guo
}

Correspondence should be addressed to B Guo

Email

guobin79@jlu.edu.cn

\begin{abstract}
Although Gja1 has been proved to play an important role in uterine decidualization, its regulatory mechanism remains largely unknown. Here, we showed that Gja1 was highly expressed in the decidual cells and promoted the proliferation of uterine stromal cells and expression of Prl8a2 and Pr/3c1, which were two well-known differentiation markers for decidualization. Further analysis revealed that Gja1 might act downstream of Acvr1 and CAMP to regulate the differentiation of uterine stromal cells. Administration of CAMP analog 8-Br-cAMP to Acvr1 siRNA-transfected stromal cells resulted in an obvious increase of Gja1 expression, whereas PKA inhibitor H89 impeded the induction of Gja1 elicited by Acvr1 overexpression, indicating that cAMP-PKA signal mediates the regulation of Acvr1 on Gja1 expression. In uterine stromal cells, knockdown of Gja1 blocked the CAMP induction of Hand2. Moreover, siRNA-mediated downregulation of Hand2 impaired the stimulatory effects of Gja1 overexpression on the expression of Prl8a2 and Prl3c1, whereas constitutive expression of Hand2 reversed the inhibitory effects of Gja1 siRNA on stromal differentiation. Meanwhile, Gja1 might play a vital role in the crosstalk between Acvr1 and Hand2. Collectively, Gja1 may act downstream of CAMP-PKA signal to mediate the effects of Acvr1 on the differentiation of uterine stromal cells through targeting Hand2.
\end{abstract}

\author{
Key Words \\ - Gja1 \\ - Acvr1 \\ - Hand2 \\ - decidualization \\ - uterine stromal cell
} (2017) 233, 145-157

\section{Introduction}

Decidualization, a process where uterine stromal cells undergo extensive proliferation and differentiation into decidual cells, is essential for continued embryonic development and successful pregnancy (Dey et al. 2004, Zhang et al. 2013). Inadequate decidualization causes embryo miscarriage and early pregnancy loss irrespective of whether development of the blastocyst is normal (Kommagani et al. 2013). It has been previously reported that activin A receptor type 1 (Acvr1, also referred to as Alk2) played an important role in modulating uterine decidualization. Conditional ablation of Acvr1 in the uterus exhibited decidualization failure in response to an artificial stimulus (Clementi et al. 2013). Although microarray analysis of oil-induced deciduoma in Acvr1deficient mice has demonstrated that decidualizationrelated gene heart and neural crest derivatives expressed transcript 2 (Hand2) was downregulated (Huyen \& Bany 2011, Clementi et al. 2013), the underlying molecular mechanism of Acvr1 remains poorly understood.

Gap junctions, which are membranous channels for the exchange of small molecules directly between/among adjacent cells or between cells and their extracellular 
environment, are critical for decidualization, because its blockade could suppress the proliferation and differentiation of uterine stromal cells (Yu et al. 2011, 2014a, Diao et al. 2013, Winterhager \& Kidder 2015, Zappitelli et al. 2015). Gap junction protein alpha 1 (Gja1), also known as connexin 43 (Cx43), was the principal and most well-studied component of the gap junctions. Loss of Gja1 expression in mouse uterus led to severe fertility defects due to the impaired stromal responsiveness to implanting embryo and deciduogenic stimulus accompanied with defective angiogenesis (Laws et al. 2008). Similar results have been obtained in human endometrial stromal cells in which attenuation of Gja1 expression disrupted the gap junctional communication between neighboring cells and impeded the differentiation of stromal cells (Laws et al. 2008, Yu et al. 2011). However, there is still very limited information available regarding the regulatory mechanism of Gja1 in the process of decidualization.

The present study was undertaken to examine the expression of Gja1 in mouse uterus during the pre-implantation period, explored its effects on the proliferation and differentiation of uterine stromal cells and focused on analyzing the interplay of Gja1, Acvr1, cAMP and Hand 2 in stromal differentiation. The results showed that Gja1 was highly expressed in the decidual cells and induced the proliferation and differentiation of uterine stromal cells. Furthermore, Gja1 might act downstream of cAMP-PKA signal to mediate the effects of Acvr 1 on the differentiation of uterine stromal cells by targeting Hand2.

\section{Materials and methods}

\section{Animal}

Matured Kunming white strain mice (6-8 weeks old) were caged in a controlled environment with a cycle of 14L:10D. All animal procedures were approved by the Institutional Animal Care and Use Committee of Jilin University. To confirm reproducibility of results, at least three mice per group were used in each stage or treatment in this study.

\section{Pregnancy and pseudopregnancy}

Adult female mice were mated with fertile or vasectomized males of the same strain to induce pregnancy or pseudopregnancy by cocaging, respectively (day $1=$ day of vaginal plug). On days 1-4, pregnancy was confirmed by recovering embryos from the oviducts or uterus. The implantation sites on day 5 were identified by intravenous injection of $0.1 \mathrm{~mL}$ of $1 \%$ Chicago blue (Sigma) in $0.85 \%$ sodium chloride.

\section{Delayed implantation and activation}

To induce delayed implantation, pregnant mice were ovariectomized under ether anesthesia at 08:30-09:00 h on day 4 of pregnancy. Progesterone (1 mg/mouse; Sigma) was injected subcutaneously to maintain delayed implantation from days 5 to 7 . Estradiol- $17 \beta$ (25 ng/ mouse, Sigma) was given to progesterone-primed delayed implantation mice to activate blastocyst implantation. The mice were killed to collect uteri $24 \mathrm{~h}$ after estrogen treatment. The implantation sites were identified by intravenous injection of Chicago blue solution. Delayed implantation was confirmed by flushing the blastocysts from the uterus.

\section{Artificial induced decidualization}

Artificial decidualization was induced by intraluminally infusing $25 \mu \mathrm{L}$ of sesame oil into one uterine horn on day 4 of pseudopregnancy, whereas the contralateral uninjected horn served as a control. The mice were killed to collect uteri at $24,48,72$ or $96 \mathrm{~h}$ after artificial-induced decidualization. Decidualization was confirmed by weighing the uterine horn and histological examination of uterine sections.

\section{In situ hybridization}

Total RNAs from the mouse uteri were reverse-transcribed and amplified with Gja1 primers. Gja1 forward primer 5'-GACTGCGGATCTCCAAAATA and reverse primer 5'-CTGTAATTCGCCCAGTTTTG were designed according to Mus musculus gap junction protein, alpha 1 (Gja1) gene (GenBank accession number NM_010288). The amplified fragment (167bp) of Gja1 was cloned into pGEM-T plasmid (pGEM-T Vector System 1; Promega) and verified by sequencing. Gja1-containing plasmid was amplified with the primers for T7 and SP6 to prepare templates for labeling. Digoxigenin (DIG)-labeled antisense and sense cRNA probes were transcribed in vitro using a DIG RNA labeling kit (Roche Diagnostics GmbH).

Frozen sections $(10 \mu \mathrm{m})$ were mounted on 3-aminopropyltriethoxy silane (Sigma)-coated slides

Published by Bioscientifica Ltd 
and fixed in 4\% paraformaldehyde solution in PBS. Hybridization was performed as described previously (Tian et al. 2013). Sections were counterstained with $1 \%$ methyl green. The positive signal was visualized as a dark brown color. The sense probe was also hybridized and served as a negative control. There was no detectable signal from sense probes.

\section{Real-time PCR}

Total RNAs from mouse uteri or cultured cells were isolated using TRIPURE reagent (Roche) according to the manufacturer's instructions, digested with RQ1 deoxyribonuclease I (Promega) to remove genomic DNA and reverse-transcribed into cDNA with M-MLV reverse transcriptase (Promega). Reverse transcription was performed at $42^{\circ} \mathrm{C}$ for $60 \mathrm{~min}$ with $2 \mu \mathrm{g}$ total RNA in $25 \mu \mathrm{L}$ volume. For real-time PCR, cDNA was amplified using FS Universal SYBR Green Real Master (Roche) on BIO-RAD

Table 1 Primers for real-time PCR.

\begin{tabular}{|c|c|c|c|}
\hline Gene & Primer sequence & $\begin{array}{l}\text { Accession } \\
\text { number }\end{array}$ & $\begin{array}{l}\text { Size } \\
\text { (bp) }\end{array}$ \\
\hline \multirow[t]{2}{*}{ Gja1 } & CGGAAGCACCATCTCCAACT & NM_010288 & 110 \\
\hline & CCACGATAGCTAAGGGCTGG & & \\
\hline \multirow[t]{2}{*}{ Cena1 } & GCCCGACGTGGATGAGTTT & NM_007628 & 132 \\
\hline & AGGAGGAATTGGTTGGTGGTT & & \\
\hline \multirow[t]{2}{*}{ Ccnb1 } & CTGAGCCTGAGCCTGAACCT & NM_172301 & 191 \\
\hline & AGCCCCATCATCTGCGTCT & & \\
\hline \multirow[t]{2}{*}{ Ccnb2 } & GCTAGCTCCCAAGGATCGTC & NM_007630 & 141 \\
\hline & CTGCAGAGCTGAGGGTTCTC & & \\
\hline \multirow[t]{2}{*}{ Cond1 } & GGGATGTGAGGGAAGAGGTGA & NM_007631 & 154 \\
\hline & GCAGCGAAAACAACGTGAAA & & \\
\hline \multirow[t]{2}{*}{ Ccnd3 } & СCTCCTACTTCCAGTGCGTG & NM_007632 & 195 \\
\hline & GGCAGACGGTACCTAGAAGC & & \\
\hline \multirow[t]{2}{*}{ Cone1 } & AATGGATGGTTCCGTTCGC & NM_007633 & 103 \\
\hline & TGGGTCTGGATGTTGTGGG & & \\
\hline \multirow[t]{2}{*}{$C d k 1$} & CTGGGCACTCCTAACAACGAAG & NM_007659 & 128 \\
\hline & TCCAAGCCGTTCTCGTCCAG & & \\
\hline \multirow[t]{2}{*}{$C d k 2$} & ACAGGGCAAGGTGAAAGAC & NM_016756 & 183 \\
\hline & AGGAGGACGGCAATGAGG & & \\
\hline \multirow[t]{2}{*}{ Cdk4 } & GTGGCTGAAATTGGTGTCGG & NM_009870 & 156 \\
\hline & TAACAAGGCCACCTCACGAA & & \\
\hline \multirow[t]{2}{*}{ Cdk6 } & TCCTGCTCCAGTCCAGCTAT & NM_009873 & 108 \\
\hline & CCACGTCTGAACTTCCACGA & & \\
\hline \multirow[t]{2}{*}{ Prl8a2 } & AGCCAGAAATCACTGCCACT & NM_010088 & 119 \\
\hline & TGATCCATGCACCCATAAAA & & \\
\hline \multirow[t]{2}{*}{$\operatorname{Pr} / 3 c 1$} & GCCACACGATATGACCGGAA & NM_001163218 & 162 \\
\hline & GGTTTGGCACATCTTGGTGTT & & \\
\hline \multirow[t]{2}{*}{ Acvr1 } & TTCGCCGGAGAAGGACTC & NM_001110205 & 178 \\
\hline & GCTGCATAGCAGATTTGGGC & & \\
\hline \multirow[t]{2}{*}{ Hand2 } & CACAGAACAAGGCCAAAGGC & NM_010402 & 161 \\
\hline & CTTGTCGTTGCTGCTCACTG & & \\
\hline \multirow[t]{2}{*}{ Gapdh } & GCCTTCCGTGTTCCTACCC & NM_008084 & 102 \\
\hline & TGCCTGCTTCACCACCTTC & & \\
\hline
\end{tabular}

CFX96TM Real-Time Detection System. The conditions used for real-time PCR were as follows: $95^{\circ} \mathrm{C}$ for $3 \mathrm{~min}$, followed by 40 cycles of $95^{\circ} \mathrm{C}$ for $15 \mathrm{~s}$ and $60^{\circ} \mathrm{C}$ for $1 \mathrm{~min}$. Water was used to replace template cDNA for negative control. All reactions were run in triplicate. The result was analyzed using CFX Manager Software. After analysis using the 2- $-\Delta \Delta \mathrm{Ct}$ method, data were normalized to Gapdh expression. Primer sequences for real-time PCR were listed in Table 1. Specificities of all primers were confirmed based on the agarose gel electrophoresis, sequencing and melting curves analysis.

\section{Isolation of uterine stromal cells}

Uterine stromal cells from day 4 of pregnancy were isolated by enzymatic digestion as previously described (Tian et al. 2013) and cultured with DMEM nutrient mixture F-12 Ham (Sigma) with 10\% heat-inactivated fetal bovine serum (Life Technologies).

\section{RNA interference}

The small-interfering RNA (siRNA) duplexes for targeting Gja1, Acvr1 and Hand2 as well as a scrambled sequence (control siRNA duplex, negative control) were synthesized by GenePharma. The sequences were as follows: 5'-CUGGGUCCUUCAGAUCAUATT and 5'-UAUGAUCUGAAGGACCCAGTT (Gja1 siRNA 1); 5'-CUCUCGCUCUGAAUAUCAUTT and 5'-AUGAUAUUCAGAGCGAGAGTT (Gja1 siRNA 2); 5'-CCUGCCGCAAUUACAACAATT and 5'-UUGUUGUAAUUGCGGCAGGTT (Gja1 siRNA 3); 5'-GGGCUGCUUUCAGGUUUAUTT and 5'-AUAAACCUGAAAGCAGCCCTT (Acvr1 siRNA 1); 5'-GGAAGUUUAAGAGACGCAATT and 5'-UUGCGUCUCUUAAACUUCCTT (Acvr1 siRNA 2); 5'-CUGUGAUGUUGAGGCAUGATT and 5'-UCAUGCCUCAACAUCACAGTT (Acvr1 siRNA 3); 5'-GCUACAUCGCCUACCUCAUTT and 5'-AUGAGGUAGGCGAUGUAGCTT (Hand2 siRNA 1); 5'-CCUUCAAGGCGGAGAUCAATT and 5'-UUGAUCUCCGCCUUGAAGGTT (Hand2 siRNA 2); 5'-GGAAGAAAGAGCUGAAUGATT and 5'-UCAUUCAGCUCUUUCUUCCTT (Hand2 siRNA 3); 5'-UUCUCCGAACGUGUCACGUTT and 5'-ACGUGACACGUUCGGAGAATT (nonspecific scrambled siRNA, negative control). Transfections for siRNA were performed according to Lipofectamine 2000 protocol. After transfection with Gja1 siRNA, Acvr1 siRNA

Published by Bioscientifica Ltd. 
or Hand2 siRNA, uterine stromal cells were collected at $24 \mathrm{~h}$.

\section{Plasmid construction and transfection}

Full-length Gja1, Acvr1 and Hand2 cDNA fragments were amplified by PCR from mouse uterus using the following primers: Gja1 (5'-AAGCTT (Hind III) ATGGGTGACTGGAGCGCCTTG and 5'-CTCGAG (Xho I) TTAAATCTCCAGGTCATCAGG), Acvr1 (5'-AAGCTT (Hind III) ATGGTCGATGGAGTAATGATC and 5'-GATATC (EcoR V) ACAAGGTCAACAGTCAGTT) and Hand2 (5'-GAATTC (EcoR I) ATGAGTCTGGTGGGGGGCTT and 5'-AAGCTT (Hind III) TCCTCTTCTTCACTGCTTG). The amplified products were purified and cloned into pGEM-T vector. The pGEM-T-Gja1, pGEM-T-Acvr1, pGEM-T-Hand2 and pcDNA3.1 vector were cut by Hind III/Xho I, Hind III/ EcoR $\mathrm{V}$ or EcoR I/Hind III (TaKaRa) at $37^{\circ} \mathrm{C}$ for $1 \mathrm{~h}$, and then, the fragments were ligated into pcDNA3.1 with T4 ligase (Promega) at $4^{\circ} \mathrm{C}$ overnight to construct pcDNA3.1-Gja1, pcDNA3.1-Acvr1 and pcDNA3.1-Hand2, respectively. An empty pcDNA3.1 expression vector was served as control. Transfection of uterine stromal cells was performed according to the manufacturer's protocol for Lipofectamine 2000 (Invitrogen). After transfection with control plasmid (empty pcDNA3.1 vector) or overexpression plasmid, stromal cells were collected at $24 \mathrm{~h}$.

\section{Cell proliferation}

Proliferation assays were performed using MTS reagent (Promega) according to the manufacturer's directions. Uterine stromal cells were seeded at a density of $1 \times 10^{5} /$ well in 96-well plates and cultured in the DMEM/F12 medium containing $2 \%$ heat-inactivated FBS. After transfection with Gja1 siRNA or overexpression plasmid, stromal cells were cultured for $24 \mathrm{~h}$. Finally, $20 \mu \mathrm{L}$ of MTS reagent was added to each well and incubated for $4 \mathrm{~h}$. Absorbance was measured at $490 \mathrm{~nm}$ using a 96-well plate reader. Every experiment was performed in triplicate.

\section{Intracellular cAMP measurement}

The intracellular cAMP levels were measured using cAMPGlo Assay (Promega) according to the manufacturer's protocol. After transfection with Acvr1 siRNA or overexpression plasmid, uterine stromal cells were cultured for $24 \mathrm{~h}$. After the removal of media, cells were incubated with the induction buffer containing $100 \mu \mathrm{M}$ Ro 20-1724 and 500 $\mu \mathrm{M}$ IBMX in the absence or presence of forskolin $(2 \mu \mathrm{M})$ for $20 \mathrm{~min}$, and then treated with cAMP-Glo Lysis Buffer accompanied by shaking. Finally, $80 \mu \mathrm{L}$ Kinase-Glo Reagent was added to each well and incubated for $10 \mathrm{~min}$ after treatment of cAMP-Glo Detection Solution. Luminescence was measured with a plate-reading luminometer. Every experiment was performed in triplicate.

\section{Statistics}

All the experiments were independently repeated at least three times. Significance of difference between two groups was compared by Independent Samples $T$ Test. The multiple comparisons were tested with one-way ANOVA. The differences were considered significant at $P<0.05$. All statistical analyses were performed using SPSS19.0 software program (SPSS).

\section{Results}

\section{Gja1 mRNA expression during early pregnancy}

In situ hybridization was used to examine the distribution of Gja1 mRNA in mouse uterus. There was no obvious Gja1 mRNA signal in the uteri from days 1 to 4 of pregnancy (Fig. 1B, C and D). On day 5 of pregnancy, Gja1 mRNA was highly expressed in the subluminal stroma surrounding the implanting blastocyst, but weakly detected at the inter-implantation sites (Fig. 1E and F). From days 6 to 8 of pregnancy, a high level of Gja1 mRNA signal was observed in the decidua (Fig. 1G, H and I). However, when Gja1 antisense probe was replaced by Gja1 sense probe, there was no corresponding signal in day 7 uterus (Fig. 1A). We next quantified the expression level of Gja1 mRNA in mouse uterus by real-time PCR. The result showed that Gja1 mRNA expression was gradually increased from days 1 to 8 of pregnancy and reached a peak on day 8 (Fig. 2A). Compared with the inter-implantation sites, Gja1 mRNA expression was higher at implantation sites on days 5-8 of pregnancy (Fig. 2B).

\section{Gja1 mRNA expression during delayed implantation and activation}

We used a delayed implantation model to determine whether Gja1 expression was dependent on the presence of an active blastocyst. The results found that there was no

Published by Bioscientifica Ltd. 

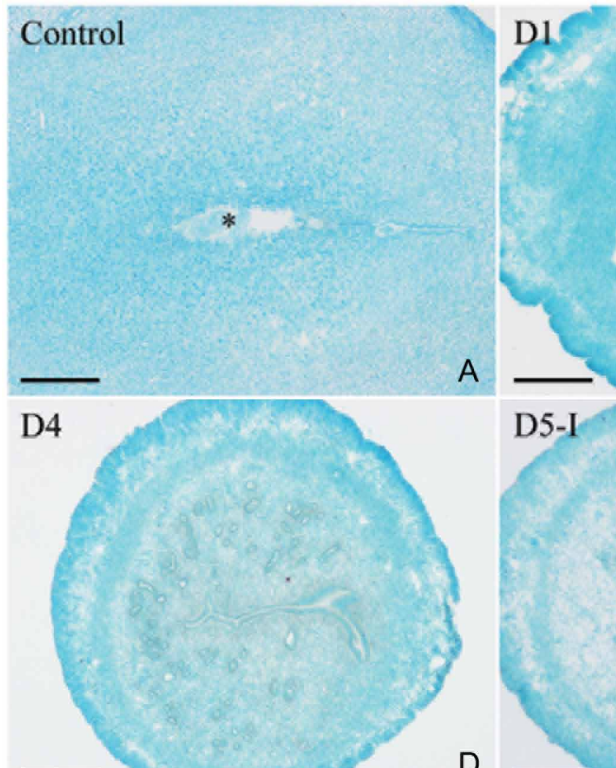

D6
A

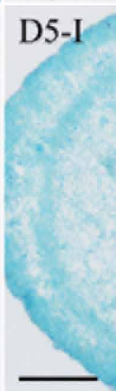

D7

G

Figure 1

In situ hybridization of Gja1 expression in mouse uteri during early pregnancy on days 1 (B), 3 (C), 4 (D), 5 (E and F), 6 (G), 7 (H) and 8 (I). No hybridization signals were seen in mouse uterus on day 7 of pregnancy when DIG-labeled Gja1 sense probe was used to replace the antisense probe as a negative control (A). 5 -I, implantation site on day 5 of pregnancy; 5 -N inter-implantation site on day 5 of pregnancy. Asterisks indicate embryo. Bar $=60 \mu \mathrm{m}$.
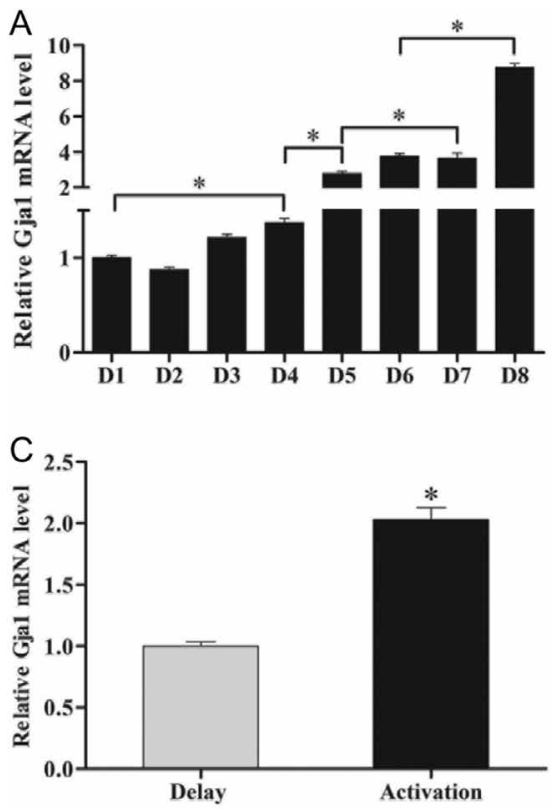
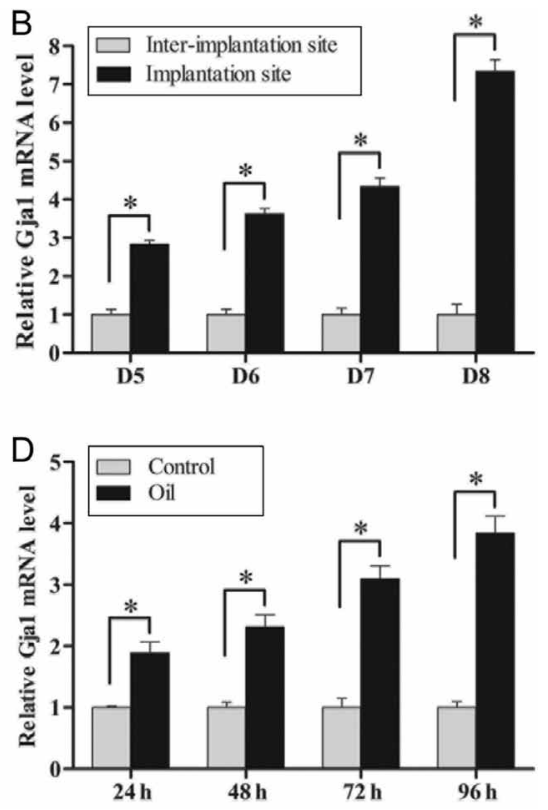

\section{Figure 2}

Real-time PCR analysis of Gja1 expression in mouse uteri. (A) Gja1 expression on days 1-8 of pregnancy. (B) Gja1 expression at the implantation sites and inter-implantation sites on days 5-8 of pregnancy. (C) Gja1 expression during delayed implantation and activation. (D) Gja1 expression under artificial decidualization. Delay, delayed implantation; Activation, activation of delayed implantation by estrogen; Control, uninjected uterine horn; Oil, oil-induced decidualization. Data are shown mean \pm S.E.M. Asterisks denote significance $(P<0.05)$. 


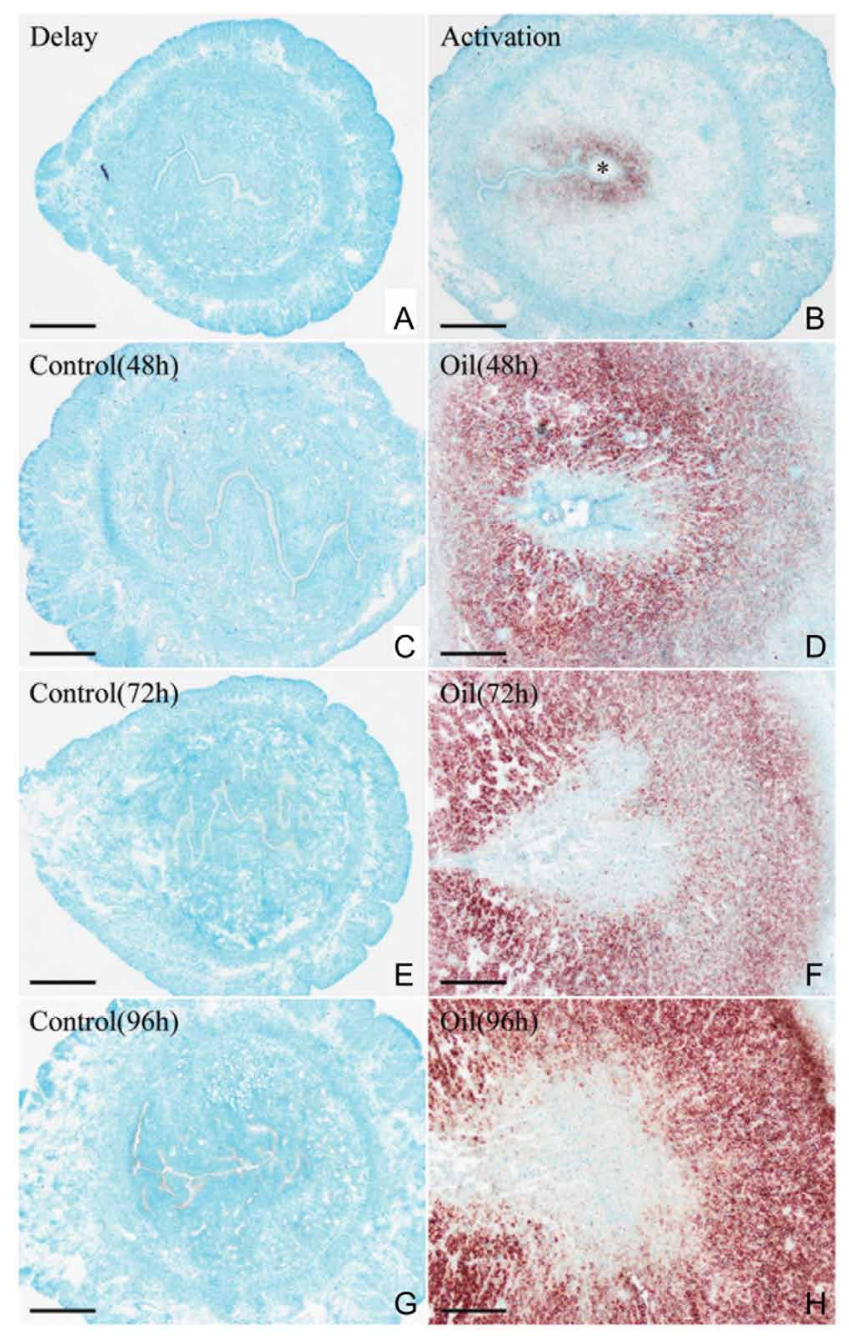

Figure 3

In situ hybridization of Gja1 expression in mouse uteri. (A) and (B) Gja1 expression during delayed implantation and activation. (C, D, E, F, $\mathrm{G}$ and $\mathrm{H}$ ) Gja1 expression under artificial decidualization.

evident Gja1 mRNA signal in the delayed uterus (Fig. 3A). After the dormant blastocyst was activated and implanted, Gja1 mRNA was visualized in the subluminal stromal cells surrounding the implanting embryo (Fig. 3B). By real-time PCR analysis, a significantly high level of Gja1 expression was detected in activated implantation uterus compared with delayed uterus (Fig. 2C).

\section{Gja1 mRNA expression under artificial decidualization}

Because Gja1 was highly expressed in the decidua, we subsequently examined its expression in an artificial induced decidualization model. As expected, Gja1 mRNA signal was clearly seen in the decidualizing stromal cells after sesame oil was injected into uterine lumen, whereas scarcely found in the uninjected control uteri (Fig. 3C, D, E, F, G and H). Simultaneously, real-time PCR results also confirmed the higher expression of Gja1 in the deciduoma compared with control, which gradually enhanced from 24 to $96 \mathrm{~h}$ as the decidua was developing and reached a maximum at $96 \mathrm{~h}$ after sesame oil injection (Fig. 2D).

\section{Effects of Gja1 on stromal cell proliferation and differentiation during decidualization}

Based on the expression pattern of Gja1 in mouse uterus, we assume that Gja1 is important for mouse decidualization. As is known to us all, stromal cell proliferation is the first step of decidualization. To investigate the role of Gja1, we synthesized three different Gja1 siRNA, transfected the uterine stromal cells and found that Gja1 siRNA 1 and 2 could apparently downregulate the expression of Gja1 mRNA compared with scrambled siRNA, but the former was more significant, whereas Gja1 siRNA 3 did not change the expression of Gja1 (Fig. 4A). Therefore, Gja1 siRNA 1 was chosen for further experiments. After transfection with Gja1 siRNA, proliferation of uterine stromal cells displayed a marked reduction compared with control (Fig. 4B). On the contrary, overexpression of Gja1 could strengthen the expression of Gja1 and proliferation activity of stromal cells (Fig. 4C and D). To further understand the molecular basis for the proliferative role of Gja1, we analyzed the effects of Gja1 on the expression of cyclin A1 (Ccna1), Ccnb1, Ccnb2, Ccnd1, Ccnd3, Ccne1, cyclin-dependent kinase 1 (Cdk1), Cdk2, Cdk4 and Cdk6. The results evidenced that silencing of Gja1 could reduce the expression of Ccnd3 and Cdk4 in the uterine stromal cells, whereas overexpression of Gja1 exhibited the opposite effects (Fig. 4E and F). Gja1 did not impact the expression of Ccna1, Ccnb1, Ccnb2, Ccnd1, Ccne1, Cdk1, $C d k 2$ and $C d k 6$ in the uterine stromal cells (Fig. 4E and F).

To study the effects of Gja1 on the differentiation of uterine stromal cells, we analyzed its effects on the expression of prolactin family 8 , subfamily a, member 2 (Prl8a2) and prolactin family 3, subfamily c, member 1 (Prl3c1), which were two well-known differentiation markers for decidualization (Clementi et al. 2013, Li et al. 2016). After Gja1 siRNA were introduced into the stromal cells, the expression of Prl8a2 and Prl3c1 was remarkably decreased (Fig. 4G). In contrast, constitutive expression of Gja1 could remarkably enhance the expression of Prl8a2 and Prl3c1 mRNA in the stromal cells (Fig. 4H). http://joe.endocrinology-journals.org DOI: 10.1530/JOE-16-0583
๑ 2017 Society for Endocrinology Printed in Great Britain 
A
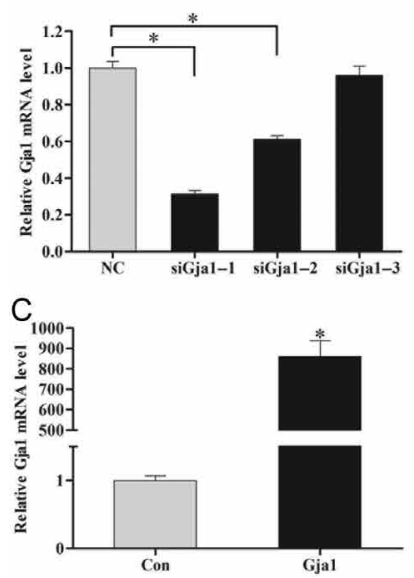

B
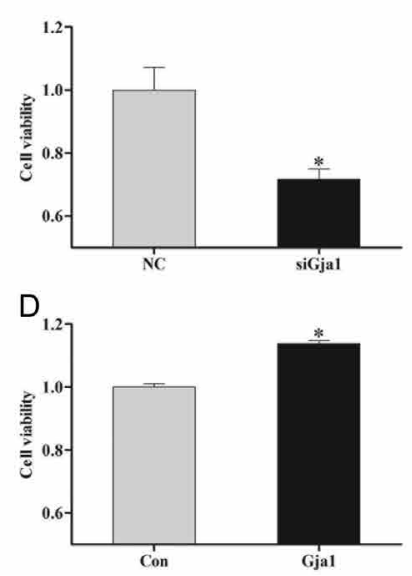
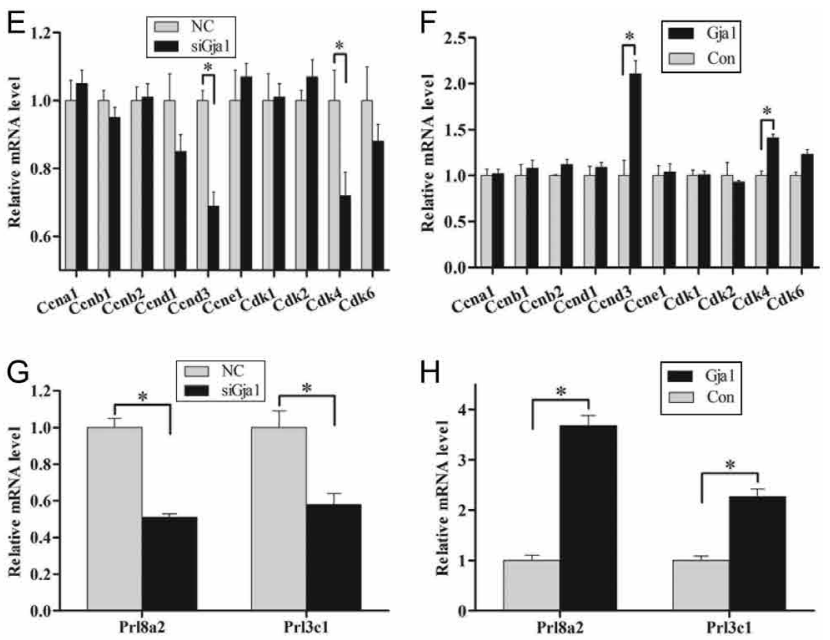

Figure 4

Effects of Gja1 on the proliferation and differentiation of uterine stromal cells. (A) Effects of Gja1 siRNAs on Gja1 mRNA expression in the uterine stromal cells. After transfection with control siRNA, Gja1 siRNA 1, siRNA 2 or siRNA 3, Gja1 mRNA expression was determined by real-time PCR. (B) Effects of Gja1 siRNA on the proliferation of uterine stromal cells. (C) Gja1 expression after uterine stromal cells were transfected with Gja1 overexpression plasmid. (D) Effects of Gja1 overexpression on the proliferation of uterine stromal cells. (E) Effects of Gja1 siRNA on the expression of Ccna1, Ccnb1, Ccnb2, Ccnd1, Ccnd3, Ccne1, Cdk1, Cdk2, Cdk4 and Cdk6. (F) Effects of Gja1 overexpression on the expression of Ccna1, Ccnb1, Ccnb2, Ccnd1, Ccnd3, Ccne1, Cdk1, Cdk2, Cdk4 and Cdk6. (G) Effects of Gja1 siRNA on the expression of Pr/8a2 and Pr/3c1. (H) Effects of Gja1 overexpression on the expression of Prl8a2 and Prl3c1. NC, control siRNA; siGja1, Gja1 siRNA; Con, empty pcDNA3.1 vector; Gja1, Gja1 overexpression plasmid.

\section{Gja1 mediates the effects of Acvr1 on the differentiation} of stromal cells

It is well known that Acvr1 was required for uterine decidualization (Clementi et al. 2013). In the stromal cells, knockdown of Acvr1 with specific siRNA could efficiently repress the expression of Acvr1, Prl8a2, Prl3c1 and Gja1, whereas overexpression of Acvr1 could augment their expression (Fig. 5A, Supplementary Fig. 1A, B, C and D, see section on supplementary data given at the end of this article). Neither attenuation nor overexpression of Gja1 had obvious impact on the expression of Acvr1 in the uterine stromal cells (Fig. 5B). We next tested whether Gja1 might mediate the effects of Acvr1 on the differentiation of stromal cells. After co-transfection with Acvr1 overexpression plasmid and Gja1 siRNA, the expression of Prl8a2 and Prl3c1 in the uterine stromal cells was evidently suppressed (Fig. 5C and D). Conversely, overexpression of Gja1 could reverse the effects of Acvr1 siRNA on the expression of Prl8a2 and Prl3c1 (Fig. 5E and F).

\section{Gja1 mediates the effects of cAMP on the differentiation of uterine stromal cells}

It has been well established that uterine decidualization was accompanied by elevated intracellular cAMP levels (Gellersen \& Brosens 2003). In the uterine stromal cells,
cAMP analog 8-bromoadenosine cAMP (8-Br-cAMP, $500 \mu \mathrm{M})$ stimulated the expression of Gja1 in a timedependent manner (Fig. 6A). As a ubiquitous second messenger, cAMP prominently activates protein kinase $\mathrm{A}$ (PKA) signal transduction pathway (Gellersen \& Brosens 2003). Addition of PKA inhibitor H89 $(10 \mu \mathrm{M})$ could block the stimulation of 8-Br-cAMP on Gja1 expression (Fig. 6B). To ascertain whether Gja1 could mediate the effects of cAMP on the differentiation of uterine stromal cells, we transfected the stromal cells with Gja1 siRNA, and then add 8-Br-cAMP and analyzed the expression of Prl8a2 and Prl3c1. The results showed that siRNA-mediated attenuation of Gja1 could impede the enhancement in the expression of Prl8a2 and Prl3c1 elicited by 8-Br-cAMP (Fig. 6C and D).

\section{Acvr1 regulates the expression of Gja1 through CAMP-PKA signal}

After uterine stromal cells were treated with 8-Br-cAMP, Acvr1 expression did not change with or without PKA inhibitor H89 (Fig. 7A and B). Knockdown of Acvr1 with specific siRNA could reduce the cAMP level in the stromal cells in the absence or presence of forskolin, an agent known to increase intracellular levels of cAMP, whereas overexpression of Acvr1 enhanced the intracellular cAMP level (Fig. 7C and D). We next study

Published by Bioscientifica Ltd. 

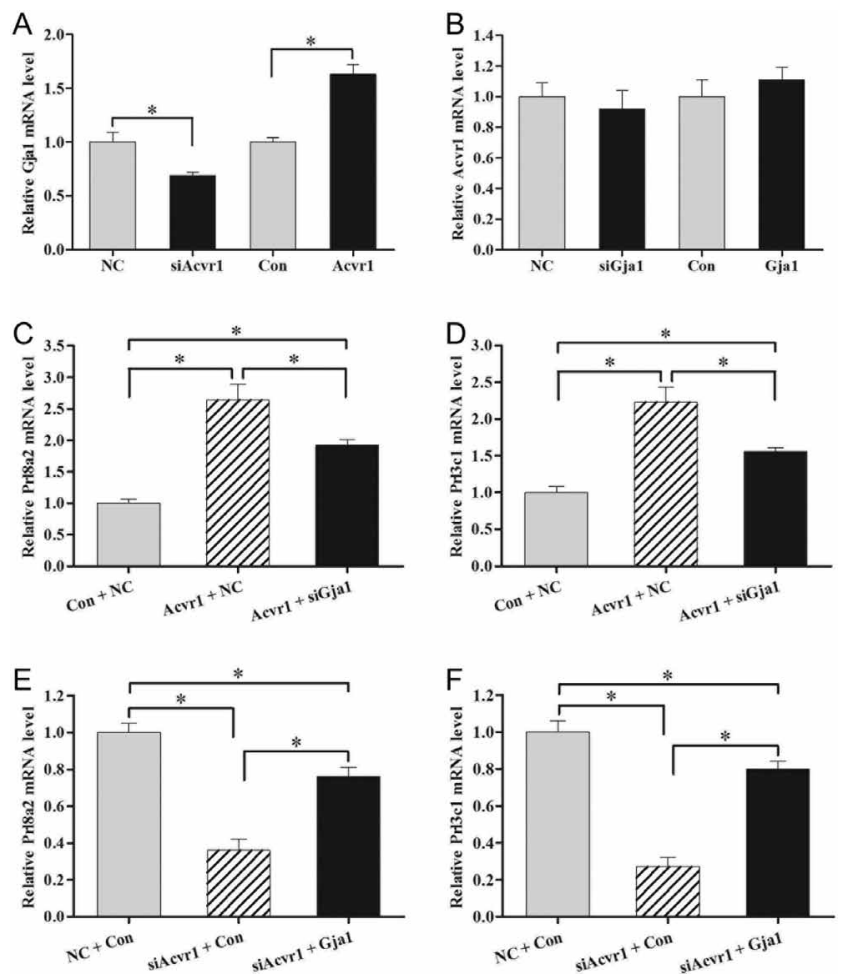

Figure 5

Gja1 mediates the effects of Acvr1 on the differentiation of uterine stromal cells. (A) Effects of Acvr1 siRNA or overexpression on the expression of Gja1. (B) Effects of Gja1 siRNA or overexpression on the expression of Acvr1. (C) and (D) Gja1 siRNA blocked the effects of Acvr1 overexpression on the expression of Prl8a2 and Prl3c1. After co-transfection with Acvr1 overexpression plasmid and Gja1 siRNA, the expression of Prl8a2 and Prl3c1 was determined by real-time PCR. (E) and (F) overexpression of Gja1 improved the effects of Acvr1 siRNA on the expression of Prl8a2 and Prl3c1. siAcvr1, Acvr1 siRNA; Acvr1, Acvr1 overexpression plasmid.

whether CAMP-PKA signal is involved in regulating the effects of $A c v r 1$ on the differentiation of uterine stromal cells. The results demonstrated that 8-Br-cAMP could improve the effects of Acvr1 siRNA on the expression of Prl8a2 and Prl3c1 in the stromal cells, whereas PKA inhibitor H89 prevented the induction of Prl8a2 and Prl3c1 by Acvr1 overexpression (Fig. 7E and F). Because Acvr1 and cAMP-PKA signal modulated the expression of Gja1 in the stromal cells, we surmised that regulation of Acvr1 on Gja1 expression was mediated by cAMPPKA signal. Indeed, after transfection with Acvr1 siRNA and then addition of 8-Br-cAMP, Gja1 expression in the stromal cells was drastically elevated (Fig. 7E). In the meantime, administration of H89 to uterine stromal cells transfected with Acvr1 overexpression plasmid resulted in a robust decline in the expression of Gja1 (Fig. 7F).
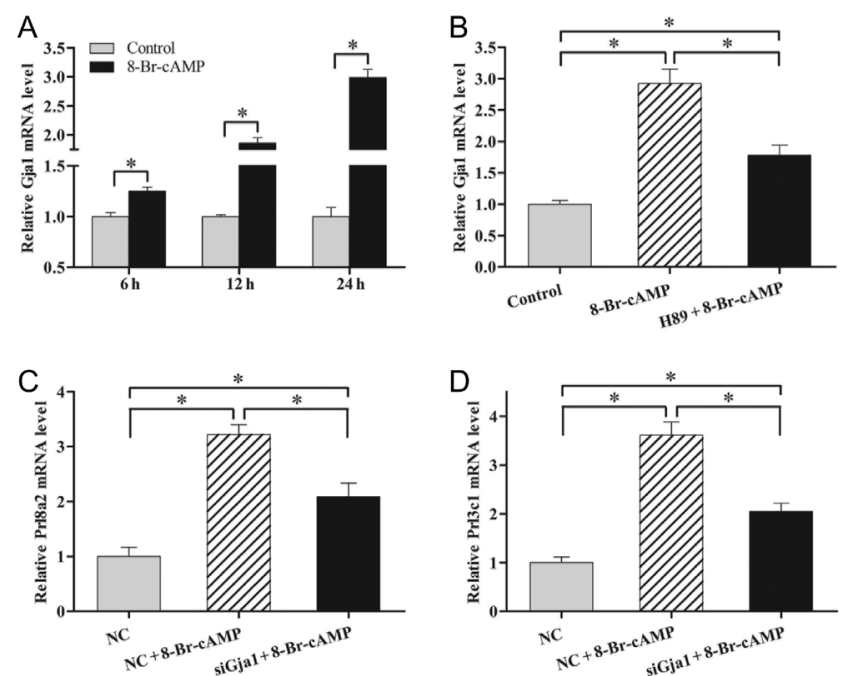

Figure 6

Gja1 mediates the effects of CAMP on the differentiation of uterine stromal cells. (A) Gja1 expression in the uterine stromal cells treated with 8-Br-cAMP for 6, 12 and 24h. (B) Gja1 expression after uterine stromal cells were treated with 8-Br-cAMP or both 8-Br-CAMP and H89. (C) and (D) Gja1 mediated the effects of CAMP on the expression of Prl8a2 and PrI3c1. After transfection with Gja1 siRNA and addition of 8-Br-CAMP, the expression of Prl8a2 and Prl3c1 was determined by real-time PCR.

\section{Gja1 regulates the differentiation of uterine stromal cells via Hand2}

Because Hand2 is expressed in the decidua and overlapped with Gja1 (Huyen \& Bany 2011), we assumed that there was a relationship between Gja1 and Hand2 during decidualization. To elucidate the relationship, we first examined the regulation of Hand2 on Gja1. Treatment with siRNA targeted to Hand2, which efficiently suppressed the level of Hand2 mRNA, led to a remarkable reduction in the expression of Prl8a2 and Prl3c1, but had no obvious impact on the expression of Gja1 (Fig. 8A, Supplementary Fig. 2A and B). Overexpression of Hand2, which could distinctly raise the expression of Hand2, Prlsa2 and Prl3c1 in the stromal cells, did not affect the expression of Gja1 (Fig. 8A, Supplementary Fig. 2C and D). Afterward, the regulation of Gja1 on Hand2 was further determined. The result evidenced that Hand2 expression was restrained by Gja1 siRNA and augmented by Gja1 overexpression (Fig. 8B). We next dissect whether Hand2 may mediate the effects of Gja1 on the differentiation of uterine stromal cells. Knockdown of Hand2 in the stromal cells with specific siRNA could impair the effects of Gja1 overexpression on the expression of Prl8a2 and Prl3c1, whereas overexpression of Hand2 compensated the effects of Gja1 silencing on the expression of Prl8a2 and Prl3c1 (Fig. 8C, D, E and F).

Published by Bioscientifica Ltd. 

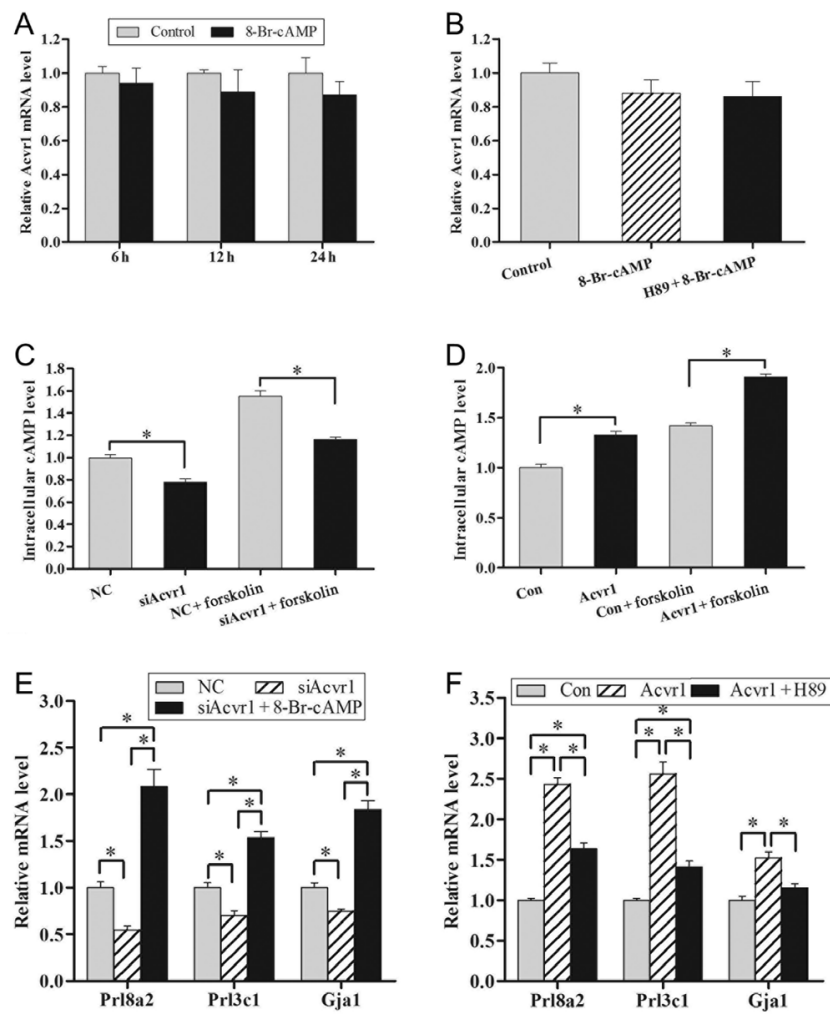

Figure 7

Acvr1 regulates the expression of Gja1 through CAMP-PKA signal. (A) Acvr1 expression in the uterine stromal cells treated with 8-Br-cAMP for 6, 12 and $24 \mathrm{~h}$. (B) Acvr1 expression after uterine stromal cells were treated with 8-Br-cAMP, or both 8-Br-cAMP and H89. (C) Effects of Acvr1 siRNA on the intracellular CAMP level in the absence or presence of forskolin. (D) Effects of Acvr1 overexpression on the intracellular CAMP level in the absence or presence of forskolin. (E) CAMP reversed the effects of Acvr1 siRNA on the expression of Prl8a2, Prl3c1 and Gja1. (F) H89 impeded the effects of Acvr1 overexpression on the expression of Prl8a2, Prl3c1 and Gja1.

\section{Gja1 mediates the regulation of cAMP on Hand2 expression}

As described previously, Gja1 could mediate the effects of cAMP on the differentiation of stromal cells and adjust the expression of Hand2. Moreover, our previous study has tested that cAMP could facilitate the expression of Hand2 in the uterine stromal cells (Li et al. 2015). The siRNA-mediated downregulation of Hand2 could alleviate the induction of 8-Br-cAMP on the expression of Prl8a2 and Prl3c1 (Fig. 8G and H). We next asked whether cAMP regulation of Hand2 expression was mediated by Gja1. After transfection with Gja1 siRNA and addition of 8-Br-cAMP, a drastic reduction of Hand2 mRNA expression was noted in the uterine stromal cells (Fig. 8I).

\section{Gja1 acts downstream of CAMP-PKA signal to mediate the regulation of Hand2 by Acvr1}

As demonstrated previously, the effects of Acvr1 on the differentiation of stromal cells were mediated by Gja1, which modulated the expression of Hand2. Based on the observation, we hypothesized that Hand2 might mediate the action of Acvr1 in stromal differentiation. To confirm the hypothesis, we first tested the interaction between Acvr1 and Hand2. The result found that silencing of Acvr1 with specific siRNA could downregulate the expression of Hand2 in the uterine stromal cells, whereas constitutive expression of Acvr1 had opposite effects (Fig. 9A). Neither inhibition nor overexpression of Hand2 altered the expression of Acvr1 in the stromal cells (Fig. 9B). Simultaneously, knockdown of Hand2 could prevent the Acvr1-induced upregulation of Prl8a2 and Prl3c1 in the uterine stromal cells (Fig. 9C and D). Conversely, overexpression of Hand 2 could improve the expression of Prl8a2 and Prl3c1 in the Acvr1 siRNA-transfected stromal cells (Fig. 9E and F). Together, these data imply that Hand2 may be a downstream target of Acvr1. We next sought to determine whether the regulation of Acvr1 on Hand2 expression was mediated by Gja1. The result revealed that attenuation of Gja1 expression in the stromal cells could abolish the induction of Acvr1 on Hand2 expression, whereas overexpression of Gja1 rescued the inhibitory effects of Acvr1 siRNA on Hand2 expression (Fig. 10A and B). Additionally, we wonder whether cAMP-PKA signal is involved in regulating the effects of Acvr1 on Hand2 expression. Administrated 8-Br-cAMP to stromal cells transfected with Acvr1 siRNA resulted in a drastic increase in the expression of Hand2 (Fig. 10C). In contrast, PKA inhibitor $\mathrm{H} 89$ eliminated the induction of Hand2 by Acvr1 overexpression (Fig. 10D).

\section{Discussion}

Gap junctions are essential for embryo implantation and decidualization, because its blockade led to an obvious reduction of the number of implanted embryos and the impairment of decidualization (Yu et al. 2011, 2014a, Diao et al. 2013, Winterhager \& Kidder 2015). As a major gap junction protein, Gja1 was weakly expressed in the mouse uteri on days 1-3 (prereceptive) and day 4 (receptive) of pregnancy and delayed implanting uteri, suggesting that Gja1 is dispensable for the transformation of uterus into the receptive state during embryo implantation. http://joe.endocrinology-journals.org DOI: 10.1530/JOE-16-0583 (c) 2017 Society for Endocrinology Printed in Great Britain 
A

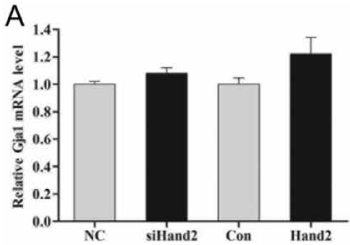

D

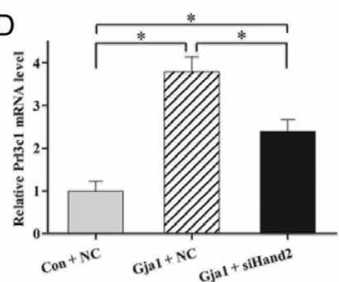

G
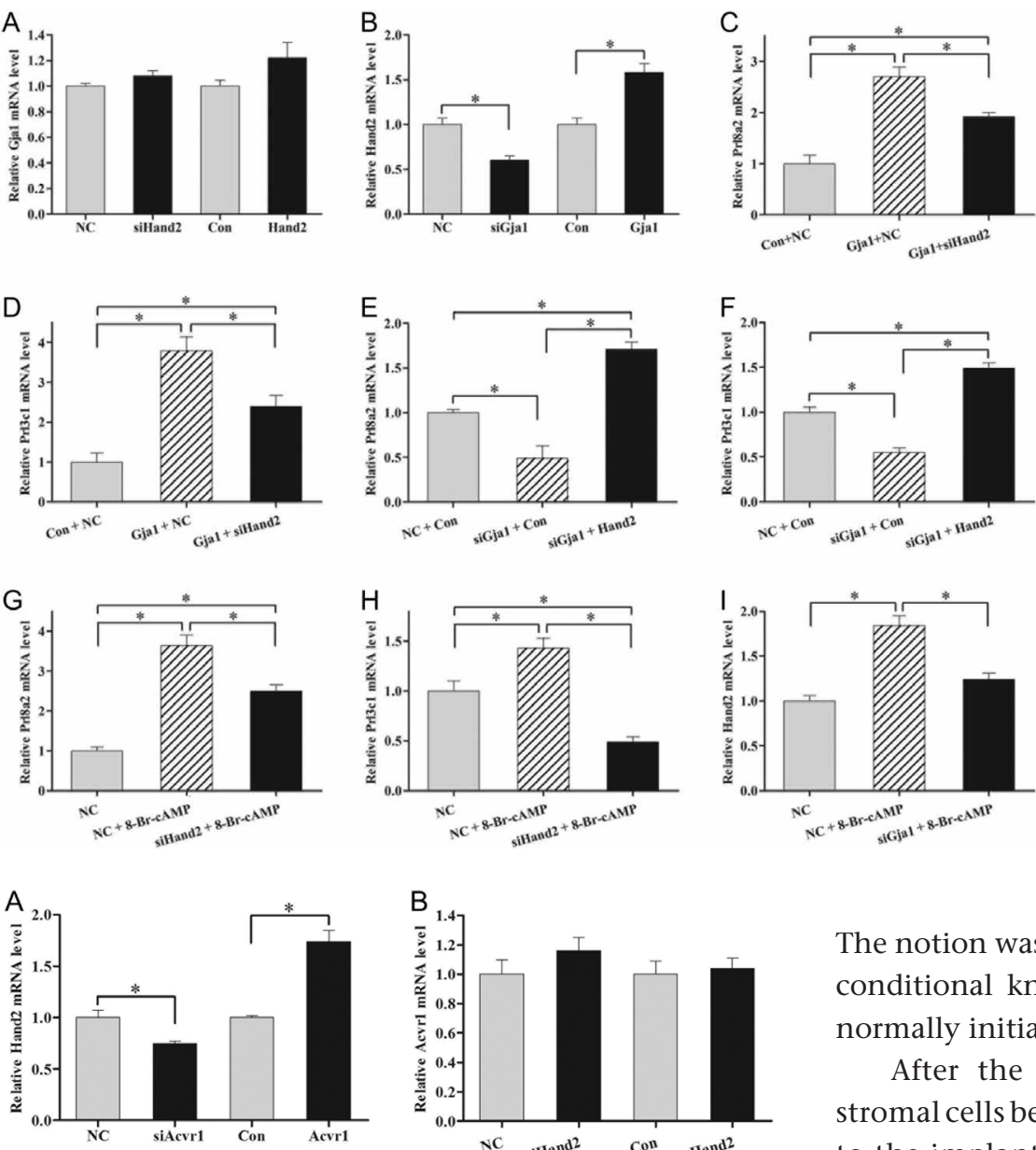
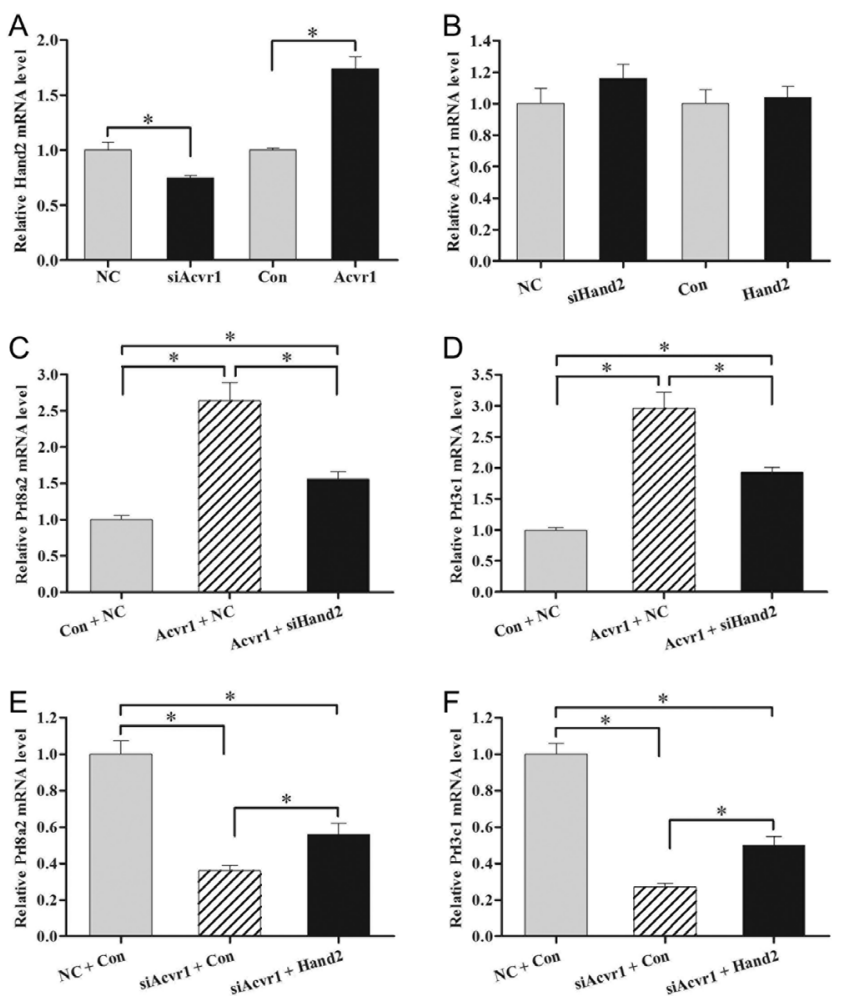

Figure 9

Hand2 mediates the effects of Acvr1 on the differentiation of uterine stromal cells. (A) Effects of Acvr1 siRNA or overexpression on the expression of Hand2. (B) Effects of Hand2 siRNA or overexpression on the expression of Acvr1. (C) and (D) Hand2 siRNA weakened the effects of Acvr1 overexpression on the expression of Prl8a2 and Prl3c1. (E) and (F) overexpression of Hand 2 improved the effects of Acvr1 siRNA on the expression of Prl8a2 and Pr/3c1.

http://joe.endocrinology-journals.org DOI: 10.1530/JOE-16-0583

C) 2017 Society for Endocrinology Printed in Great Britain
The notion was also supported by previous reports, which conditional knockdown of Gja1 in mouse uterus could normally initiate embryo implantation (Laws et al. 2008).

After the onset of embryo implantation, uterine stromal cells begin to undergo decidualization in response to the implanting embryo (Dey et al. 2004, Zhang et al. 2013). With the progression of decidualization, elevated expression of Gja1 mRNA was observed in the decidual cells, suggesting a role of Gja1 in decidualization. Stromal cell proliferation is the first step of decidualization (Chen et al. 2009, Zhang et al. 2013). Inhibition of Gja1 by specific siRNA reduced the proliferation of uterine stromal cells, whereas overexpression of Gja1 exhibited the opposite effects. Similarly, blockade of Gja1-mediated gap junction weakened the proliferation of human endometrial stromal cells (Yu et al. 2014a). It is well known that the proliferation of mammalian cells is controlled by cyclins and Cdks (Wang et al. 2010). In the uterine stromal cells, Gja1 modulates the expression of Ccnd3 and Cdk4, indicating that Gja1 regulates stromal cells proliferation by targeting $C c n d 3$ and $C d k 4$. Along with this noticeable proliferation, stromal cells differentiate into decidual cells (Zhang et al. 2013). Conditional deletion of Gja1 impaired the differentiation of uterine stromal cells in mice (Laws et al. 2008). Similar results have been obtained in human endometrial stromal cells in which attenuation of Gja1 expression could impede stromal differentiation (Laws et al. 2008,

Published by Bioscientifica Ltd 
A
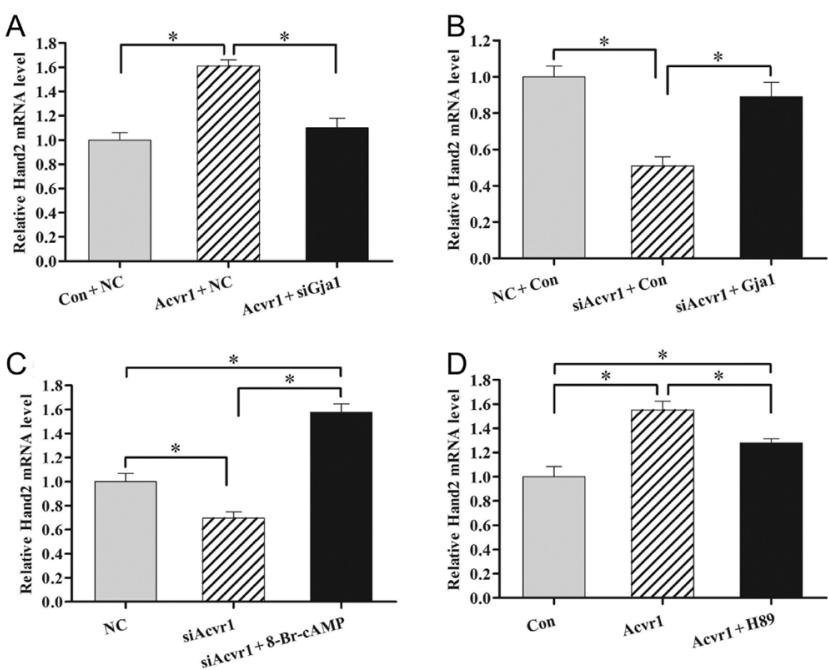

Figure 10

Gja1 acts downstream of CAMP-PKA signal to mediate the regulation of Acvr1 on Hand2 expression. (A) Gja1 siRNA abrogated the effects of Acvr1 overexpression on Hand2 expression. (B) Overexpression of Gja1 rescued the effects of Acvr1 siRNA on Hand2 expression. (C) CAMP reversed the effects of Acvr1 siRNA on Hand2 expression. (D) H89 impeded the effects of Acvr1 overexpression on Hand2 expression.

Yu et al. 2011). The present study has reinforced the importance of Gja1 in the differentiation of uterine stromal cells. Moreover, reduced Gja1 expression was

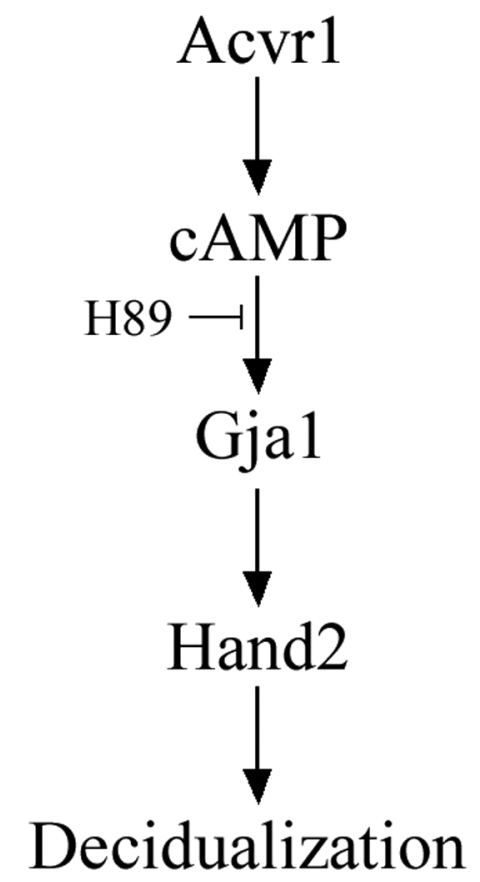

\section{Figure 11}

Schematic diagram shows the involvement of Gja1 during decidualization. Gja1 may act downstream of CAMP-PKA signal to mediate effects of Acvr1 on the differentiation of uterine stromal cells through targeting Hand2. also noted in the decidua and endometrial stromal cells of women with recurrent early pregnancy loss and endometriosis, respectively (Nair et al. 2011, Yu et al. 2014b, Winterhager \& Kidder 2015). Together these data demonstrate that Gja1 plays an important role in the proliferation and differentiation of uterine stromal cells. Further analysis found that Gja1 could regulate the expression of Hand2 whose knockdown damaged the uterine stromal differentiation in both mice and human (Huyen \& Bany 2011). Overexpression of Hand2 could rescue the effects of Gja1 siRNA on the expression of Prl8a2 and Prl3c1, whereas attenuation of Hand2 expression by siRNA prevented the upregulation of Prl8a2 and Prl3c1 elicited by Gja1 overexpression. These results provide convincing evidence that Hand2 is a critical mediator of Gja1 function in the differentiation of uterine stromal cells.

It has previously been reported that Gja1, as the major component of gap junctions, might mediate the gap junctional communication among endometrial stromal cells (Laws et al. 2008, Yu et al. 2011). Intriguingly, the present study revealed that Gja1 could modulate the expression of Ccnd3, Cdk4 and Hand2 genes. Simultaneously, there was a considerable amount of evidence to support the similar notion by these findings that deficiency of Gja1 in the heart, testicular Sertoli cells, astrocytes and glioblastoma cells led to the downregulation and upregulation of numerous genes by microarray analysis (Huang et al. 2002, Iacobas et al. 2003, 2005, Giese et al. 2012). The reason was probably due to the interaction of Gja1 with these proteins involved in gene transcription. Indeed, accumulating data have identified a lot of Gja1-interacting partners (Butkevich et al. 2004, Singh et al. 2005, Dai et al. 2007, Martins-Marques et al. 2015). However, the regulatory mechanisms of Gja1 on the expression of Ccnd3, Cdk4 and Hand2 in uterine stromal cells remain to be determined.

It is generally accepted that Acvr1 is of great importance to uterine decidualization (Clementi et al. 2013). In female mice with uterine-specific deficiency of Acvr1, stromal cells failed to undergo decidualization (Clementi et al. 2013). The present study found that the effects of Acvr1 on the differentiation of uterine stromal cells were mediated by Gja1. Meanwhile, in the absence of Acvr1, Hand2 expression in oil-induced deciduoma was significantly downregulated (Clementi et al. 2013). Consistent with the observation, Hand2 was also regulated by Acvr1 in the uterine stromal cells and has been proved be a crucial participant in Acvr1-mediated

Published by Bioscientifica Ltd. 
stromal differentiation. Overexpression of Gja1 could improve the expression of Hand2 in the Acvr1 siRNAtransfected stromal cells, whereas silencing of Gja1 abolished the induction of Acvr1 on Hand2 expression, implying that Gja1 may play an important role in the crosstalk between Acvr1 and Hand2.

It has been well established that initiation of the decidual process requires elevated intracellular cAMP levels (Gellersen \& Brosens 2003). In mouse embryonic stem cells, thymic epithelial cells and IMR-32 neuroblastoma cells, cAMP analog 8-Br-cAMP could upregulate the expression of Gja1 (Arnold et al. 2005, Nihei et al. 2010, Yun et al. 2012). The similar result was also observed in the uterine stromal cells. As a ubiquitous second messenger, cAMP can prominently activate the PKA signal pathway (Gellersen \& Brosens 2003). PKA inhibitor H89 abrogated the stimulation of 8-Br-cAMP on Gja1 expression. Moreover, siRNAmediated downregulation of Gja1 expression greatly lessened cAMP-induced stromal differentiation as evidenced by the drastically reduced expression of Prl8a2 and Prl3c1, suggesting Gja1 requirement for the cAMP action on stromal differentiation. Further study found that 8-Br-cAMP could reverse the inhibitory effects of Acvr1 siRNA on Gja1 expression, whereas H89 eliminated the induction of Gja1 elicited by Acvr1 overexpression, indicating that cAMP-PKA signal is involved in the regulation of Acvr1 on Gja1 expression.

In summary, the present study unravels a linear pathway involving Gja1, Acvr1, cAMP and Hand2 during decidualization. We show that Gja1 may act downstream of cAMP-PKA signal to mediate the effects of Acvr1 on the differentiation of uterine stromal cells through targeting Hand2 (Fig. 11).

\section{Supplementary data}

This is linked to the online version of the paper at http://dx.doi.org/10.1530/ JOE-16-0583.

\section{Declaration of interest}

The authors declare that there is no conflict of interest that could be perceived as prejudicing the impartiality of the research reported.

\section{Funding}

This work was financially supported by National Natural Science Foundation of China (31472158, 31372390 and 31672503) and Special Funds for Scientific Research on Public Causes (201303119).

\section{References}

Arnold JM, Phipps MW, Chen J \& Phipps J 2005 Cellular sublocalization of $\mathrm{Cx} 43$ and the establishment of functional coupling in IMR32 neuroblastoma cells. Molecular Carcinogenesis 42 159-169. (doi:10.1002/mc.20072)

Butkevich E, Hülsmann S, Wenzel D, Shirao T, Duden R \& Majoul I 2004 Drebrin is a novel connexin-43 binding partner that links gap junctions to the submembrane cytoskeleton. Current Biology 14 650-658. (doi:10.1016/j.cub.2004.03.063)

Chen L, Belton RJ Jr \& Nowak RA 2009 Basigin-mediated gene expression changes in mouse uterine stromal cells during implantation. Endocrinology 150 966-976. (doi:10.1210/en.2008-0571)

Clementi C, Tripurani SK, Large MJ, Edson MA, Creighton CJ, Hawkins SM, Kovanci E, Kaartinen V, Lydon JP, Pangas SA, et al. 2013 Activin-like kinase 2 functions in peri-implantation uterine signaling in mice and humans. PLoS Genetics 9 e1003863. (doi:10.1371/journal. pgen.1003863)

Dai P, Nakagami T, Tanaka H, Hitomi T \& Takamatsu T 2007 Cx43 mediates TGF-beta signaling through competitive Smads binding to microtubules. Molecular Biology of the Cell 18 2264-2273. (doi:10.1091/mbc.E06-12-1064)

Dey SK, Lim H, Das SK, Reese J, Paria BC, Daikoku T \& Wang H 2004 Molecular cues to implantation. Endocrine Reviews 25 341-373. (doi:10.1210/er.2003-0020)

Diao H, Xiao S, Howerth EW, Zhao F, Li R, Ard MB \& Ye X 2013 Broad gap junction blocker carbenoxolone disrupts uterine preparation for embryo implantation in mice. Biology of Reproduction 8931. (doi:10.1095/biolreprod.113.110106)

Gellersen B \& Brosens J 2003 Cyclic AMP and progesterone receptor cross-talk in human endometrium: a decidualizing affair. Journal of Endocrinology 178 357-372. (doi:10.1677/joe.0.1780357)

Giese S, Hossain H, Markmann M, Chakraborty T, Tchatalbachev S, Guillou F, Bergmann M, Failing K, Weider K \& Brehm R 2012 Sertolicell-specific knockout of connexin 43 leads to multiple alterations in testicular gene expression in prepubertal mice. Disease Models and Mechanisms 5 895-913. (doi:10.1242/dmm.008649)

Huang R, Lin Y, Wang CC, Gano J, Lin B, Shi Q, Boynton A, Burke J \& Huang RP 2002 Connexin 43 suppresses human glioblastoma cell growth by down-regulation of monocyte chemotactic protein 1 , as discovered using protein array technology. Cancer Research $\mathbf{6 2}$ 2806-2812.

Huyen DV \& Bany BM 2011 Evidence for a conserved function of heart and neural crest derivatives expressed transcript 2 in mouse and human decidualization. Reproduction 142 353-368. (doi:10.1530/REP11-0060)

Iacobas DA, Urban-Maldonado M, Iacobas S, Scemes E \& Spray DC 2003 Array analysis of gene expression in connexin-43 null astrocytes. Physiological Genomics 15 177-190. (doi:10.1152/ physiolgenomics.00062.2003)

Iacobas DA, Iacobas S, Li WE, Zoidl G, Dermietzel R \& Spray DC 2005 Genes controlling multiple functional pathways are transcriptionally regulated in connexin43 null mouse heart. Physiological Genomics 20 211-223. (doi:10.1152/physiolgenomics.00229.2003)

Kommagani R, Szwarc MM, Kovanci E, Gibbons WE, Putluri N, Maity S, Creighton CJ, Sreekumar A, DeMayo FJ, Lydon JP, et al. 2013 Acceleration of the glycolytic flux by steroid receptor coactivator- 2 is essential for endometrial decidualization. PLoS Genetics 9 e1003900. (doi:10.1371/journal.pgen.1003900)

Laws MJ, Taylor RN, Sidell N, DeMayo FJ, Lydon JP, Gutstein DE, Bagchi MK \& Bagchi IC 2008 Gap junction communication between uterine stromal cells plays a critical role in pregnancy-associated neovascularization and embryo survival. Development 135 2659-2668. (doi:10.1242/dev.019810)

Li DD, Guo CH, Yue L, Duan CC, Yang ZQ, Cao H, Guo B \& Yue ZP 2015 Expression, regulation and function of Hmgn3 during http://joe.endocrinology-journals.org

DOI: 10.1530/JOE-16-0583
C 2017 Society for Endocrinology Printed in Great Britain 
decidualization in mice. Molecular and Cellular Endocrinology $\mathbf{4 1 3}$ 13-25. (doi:10.1016/j.mce.2015.05.038)

Li DD, Zhao SY, Yang ZQ, Duan CC, Guo CH, Zhang HL, Geng S, Yue ZP \& Guo B 2016 Hmgn5 functions downstream of Hoxa10 to regulate uterine decidualization in mice. Cell Cycle 15 2792-2805. (doi:10.108 0/15384101.2016.1220459)

Martins-Marques T, Anjo SI, Pereira P, Manadas B \& Girão H 2015 Interacting network of the gap junction (GJ) protein Connexin43 (Cx43) is modulated by ischemia and reperfusion in the heart. Molecular and Cellular Proteomics 14 3040-3055. (doi:10.1074/mcp. M115.052894)

Nair RR, Jain M \& Singh K 2011 Reduced expression of gap junction gene connexin 43 in recurrent early pregnancy loss patients. Placenta 32 619-621. (doi:10.1016/j.placenta.2011.05.010)

Nihei OK, Fonseca PC, Rubim NM, Bonavita AG, Lyra JS, Neves-dosSantos S, de Carvalho AC, Spray DC, Savino W \& Alves LA 2010 Modulatory effects of cAMP and PKC activation on gap junctional intercellular communication among thymic epithelial cells. BMC Cell Biology 11 3. (doi:10.1186/1471-2121-11-3)

Singh D, Solan JL, Taffet SM, Javier R \& Lampe PD 2005 Connexin 43 interacts with zona occludens- 1 and -2 proteins in a cell cycle stagespecific manner. Journal of Biological Chemistry $28030416-30421$. (doi:10.1074/jbc.M506799200)

Tian XC, Wang QY, Li DD, Wang ST, Yang ZQ, Guo B \& Yue ZP 2013 Differential expression and regulation of Cryab in mouse uterus during preimplantation period. Reproduction 145 577-585. (doi:10.1530/REP-13-0042)

Wang W, Li Q, Bagchi IC \& Bagchi MK 2010 The CCAAT/enhancer binding protein $\beta$ is a critical regulator of steroid-induced mitotic expansion of uterine stromal cells during decidualization. Endocrinology 151 3929-3940. (doi:10.1210/en.2009-1437)
Winterhager E \& Kidder GM 2015 Gap junction connexins in female reproductive organs: implications for women's reproductive health. Human Reproduction Update 21 340-352. (doi:10.1093/humupd/ dmv007)

Yu J, Wu J, Bagchi IC, Bagchi MK, Sidell N \& Taylor RN 2011 Disruption of gap junctions reduces biomarkers of decidualization and angiogenesis and increases inflammatory mediators in human endometrial stromal cell cultures. Molecular and Cellular Endocrinology 344 25-34. (doi:10.1016/j.mce.2011.04.011)

Yu J, Berga SL, Zou W, Sun HY, Johnston-MacAnanny E, Yalcinkaya T, Sidell N, Bagchi IC, Bagchi MK \& Taylor RN 2014a Gap junction blockade induces apoptosis in human endometrial stromal cells. Molecular Reproduction and Development 81 666-675. (doi:10.1002/ mrd.22334)

Yu J, Boicea A, Barrett KL, James CO, Bagchi IC, Bagchi MK, Nezhat C, Sidell N \& Taylor RN 2014b Reduced connexin 43 in eutopic endometrium and cultured endometrial stromal cells from subjects with endometriosis. Molecular Human Reproduction 20 260-270. (doi:10.1093/molehr/gat087)

Yun SP, Park SS, Ryu JM, Park JH, Kim MO, Lee JH \& Han HJ 2012 Mechanism of PKA-dependent and lipid-raft independent stimulation of Connexin43 expression by oxytoxin in mouse embryonic stem cells. Molecular Endocrinology 26 1144-1157. (doi:10.1210/me.2011-1343)

Zappitelli T, Chen F \& Aubin JE 2015 Up-regulation of BMP2/4 signaling increases both osteoblast-specific marker expression and bone marrow adipogenesis in Gja1 Jrt/+ stromal cell cultures. Molecular Biology of the Cell 26 832-842. (doi:10.1091/mbc.E14-06-1136)

Zhang S, Lin H, Kong S, Wang S, Wang H, Wang H \& Armant DR 2013 Physiological and molecular determinants of embryo implantation. Molecular Aspects of Medicine 34 939-980. (doi:10.1016/j. mam.2012.12.011)

Received in final form 10 February 2017

Accepted 20 February 2017

Accepted Preprint published online 20 February 2017
() 2017 Society for Endocrinology Printed in Great Britain 